\title{
¿QUÉ AMÉRICA ES ÉSTA? SOBREVIVENCIAS DE LA \\ COLONIZACIÓN EUROPEA DE INDOAMÉRICA, EJEMPLIFICANDO CON LOS CASOS DE BRASIL Y ARGENTINA
}

\author{
Eduardo A. Vizer - Helenice Carvalho \\ Universidade Federal do Rio Grande do Sul
}

\begin{abstract}
"Somos um país que se perdeu na história, que se perdeu de si mesmo, que se desencontrou de sua gente e do seu destino."

(Luís Roberto Barroso) $^{1}$
\end{abstract}

\begin{abstract}
Resumen: Este trabajo pretende en primer lugar abordar ciertas diferencias significativas entre tres procesos de colonización que fueron impuestos a los territorios y los pueblos originarios de las Américas. Aparte de la colonización francesa en el Québéc canadiense en los dos primeros siglos (XVII y parte del XVIII), las tres colonizaciones dominantes fueron la inglesa en Norteamérica, la portuguesa en el actual Brasil y las conquistas españolas en el resto de América del Sur y Central. En segundo lugar, el trabajo pretende abordar ciertas sobrevivencias sociales y culturales que aún perduran en las Américas luego de dos siglos de independencia de las metrópolis. En tercer lugar pretendemos desmentir ciertos presupuestos sobre la latinidad de los países de habla castellana y portuguesa. Consideramos que uno de los ejes históricos fundamentales a tomar en cuenta al analizar las formas de origen de las políticas y el estado en estos países estriba en la forma en que consiguieron su independencia y sus intentos de construcción del estado en relación con las tres coronas: la inglesa, la española y la portuguesa.
\end{abstract}

Palabras clave: estado, Indoafroamérica, colonización, republicanismo

\begin{abstract}
This paper addresses significant differences between three processes of colonization that were imposed over the territories and the native peoples of the Americas. Beside the french in Canadian Québec in the first two centuries (XVII and part of the XVIII), the three dominant colonizations were the english in North America, the portuguese in present Brazil, and the spanish conquests in the rest of South and Central America. Secondly, the paper aims to address certain social and cultural attitudes and institutional aspects that still survive in the Americas after two centuries of Independence of the metropolis. Thirdly, we intend to deny certain common assumptions about the latinity of the Spanish and Portuguese speaking countries. We
\end{abstract}

\footnotetext{
${ }^{1}$ Ministro Luís R. Barroso, del Supremo Tribunal del Brasil (STF), refiriéndose a Brasil, publicada en la revista Carta Capital del 16 de agosto de 2017, cuando el texto ya estaba finalizado.
} 
¿Qué América es ésta? Sobrevivencias de la colonización europea de Indoamérica, ejemplificando con los casos de Brasil y Argentina

consider that one of the fundamental historical axes to be taken into account when analyzing the forms and origins of policies and the construction of the State in these countries rests in the form in which they obtained their independence and their attempts to reconstruct the State in reference to the three crowns: the English, the Spanish and the Portuguese.

Keywords: State, Indo-afro-America, colonization, republicanism

\section{Introducción}

En primer lugar, hay que aclarar que América Latina no es "latina", ni en el sur ni en el centro del continente americano. Es sobre todo una región geográfica que podemos dividir en tres partes (incluyendo Centroamérica). O en dos: América del Norte predominantemente francoanglosajona (Estados Unidos, Canadá, excepto México) y América del Sur indoafrolatina, que desde esta perspectiva demográfica incluiría también América Central. Por esto, hablar de América Latina es un cliché europeísta, a menos que dejemos a un lado la naturaleza étnica y consideremos las lenguas predominantes: español, portugués, inglés y finalmente francés y las numerosas lenguas nativas.

La razón por la que preferimos referirnos a Indoafroamérica en vez de Latinoamérica se verá en las páginas siguientes. Una diferencia fundamental entre ambas Américas está en que el norte desarrollado con hegemonía anglosajona presenta sociedades de historia reciente -algo más que dos siglos, a excepción del Québéc que antecede la colonización anglosajona- donde se observan estados sólidamente organizados y establecidos de acuerdo con instituciones modernas, un régimen político liberal-democrático y economía capitalista avanzada. Ya en el centro y sur se presenta un conglomerado heterogéneo de culturas, lenguas y sociedades que se hallan en una permanente búsqueda, construcción y adaptación de instituciones adecuadas a sociedades diversas y multiculturales (con el ejemplo de Evo Morales en Bolivia como presidente indígena aymará elegido para presidir las diferentes naciones que componen el país). En estos países se produce una amalgama compleja y no siempre exitosa de tradiciones nativas autóctonas, de poblaciones transplantadas a la fuerza (los esclavos traídos de África durante casi tres siglos) y pobladores de origen sobre todo latino (español, portugués y europeo en general). A comienzos del siglo XIX, Haití y las colonias españolas aprovechan la invasión napoleónica que descabeza las coronas portuguesa y española para comenzar guerras de independencia de casi 20 años (de 1810 a 1826 aproximadamente). A excepción de 
Puerto Rico y Cuba -que solamente logra su independencia condicionada a los Estados Unidos tras la guerra entre ésta y España a fines del XIX- todas estas guerras son exitosas y se logra la independencia de nuevos países. La conformación institucional de estos estados es un proceso conflictivo y violento entre minorías urbanas y poblaciones (generalmente rurales) que no se sienten representadas en las nuevas instituciones de corte liberal importadas de Europa y exigidas por sectores urbanos generalmente ligados al libre comercio y la libre navegación de los ríos, y no a la defensa de la producción autóctona tradicional (la producción textil representa una fuente de conflicto permanente con el ingreso de las telas inglesas o francesas producidas a bajo precio y masivamente con telares y nuevas máquinas de producción en masa). Las guerras civiles y los conflictos interregionales y de clase demandan prácticamente medio siglo de luchas, desde 1810 a 1850 o 60.

La mayoría son sociedades heterogéneas y multiétnicas (indoafrolatinas), que luego de independizarse de la Corona Española sufren dolorosos procesos de conflicto y de "prueba y error" para la construcción de formas institucionales y estatales mas inclusivas, y en última instancia modernas y adaptadas no solo al contexto y el mercado europeo dominante sino a las demandas y presiones de las poblaciones nativas tradicionales, así como también a los intereses de los sectores económica y políticamente dominantes de origen español o portugués (en Brasil). Estos sectores se asocian al mercado internacional en forma incipiente (sobre todo a Inglaterra) en todos los países y casos, y así estas minorías ilustradas buscan imponer la legitimidad de sus demandas al presentarse como únicos actores modernos, racionales e instruidos de sus sociedades. Las mayorías nativas son generalmente obligadas (por la espada y por el poder simbólico que emana de la Ilustración europea a la cual no pueden acceder) a enfrentar los intereses económicos y políticos de las elites de las ciudades con los medios tradicionales que sirvieron para la construcción de una economía casi artesanal que había proveído a las necesidades locales por siglos.

Completamente opuesto fue el caso de los estados del oeste y del norte de Norteamérica, donde desde el comienzo del poblamiento a partir del siglo XVII se forman colonias de origen inglés, escocés e irlandés (o francés en Québéc y Luisiana). La Corona Inglesa establece la frontera de las 13 colonias originales con las poblaciones nativas, pero en el siglo XIX éstas son prácticamente destruidas o remitidas a "reservas indígenas" a finales del siglo XIX. La población exclusivamente europea provenía de una inmigración marcada por la 
¿Qué América es ésta? Sobrevivencias de la colonización europea de Indoamérica, ejemplificando con los casos de Brasil y Argentina

rebeldía y el rechazo al poder centralizado de monarcas generalmente de fuerte tendencia absolutista (sobre todo en España y Portugal). La inmigración que se establece en el norte, también había sufrido múltiples persecuciones, motivada por la búsqueda de la libertad religiosa, el establecimiento de colonias y nuevas congregaciones protestantes, o una fuga de las políticas de segregación europeas, o bien buscando nuevas posibilidades económicas y de acceso a la propiedad de la tierra (negada en Europa y también en las colonias españolas). Los inmigrantes del norte de América no buscan apropiarse del oro y de los tesoros indígenas como en el caso de los conquistadores ibéricos, su Eldorado es el derecho a la posesión de la tierra para ser trabajada, y mejores condiciones de vida en un nuevo continente con acceso a la tierra y a medios de trabajo que abrieran para sus hijos un futuro a ser construido con el propio esfuerzo, y no meramente una acomodación a las limitaciones de las estructuras económicas, políticas y religiosas del viejo mundo.

Para entender las diferencias capitales que explican las particularidades históricas entre el norte y el sur, es importante señalar las características centrales y definitorias de tres tipos de colonización en las Américas. Empecemos por la española: la conquista española fue históricamente marcada por una tradición de siete siglos de lucha contra el ocupante árabe, siempre concebido como invasor e infiel. Los reyes ibéricos habían buscado la reconquista de territorios españoles que debían ser reconquistados de los moros palmo a palmo, en nombre de la cruz cristiana y por medio de la espada (la espada y la cruz se inscriben como símbolos de una cruzada cristiana en el oeste ibérico de Europa, mientras se desarrollan las cruzadas salvajes contra el Islam en el este, generando en Europa una mentalidad de resistencia al asedio árabe, que en el siglo XXI en cierta medida es proyectada como miedo y xenofobia hacia los inmigrantes musulmanos que escapan de guerras y del fundamentalismo islámico). En América se siguió una estrategia similar: conquistar territorios y riqueza para la cristiandad por medio de las armas, a partir de la destrucción de las culturas nativas y la apropiación del oro y las riquezas naturales en nombre del monarca, además de la adjudicación de enormes masas de tierra a conquistadores y nobles. Nada debía quedar en las Américas sin algún propietario ibérico, en especial de origen noble.

Un segundo caso se da con la colonización portuguesa, tal vez en parte por lo reducido de la capacidad demográfica y económica pero sobre todo por las características portuguesas de establecer bases marítimas para el comercio en 
África y Asia. Así se buscó construir establecimientos comerciales sobre la costa del Brasil, sin interesarse demasiado por la colonización del interior, siempre acosado por aventureros y bandeirantes. Las ciudades costeras operarían como intermediarias entre la producción de madera (Pau Brazil), caña y luego el café y el algodón, para así suplir las demandas del comercio internacional. Diferentemente, España buscaba además de las riquezas naturales, colonizar y establecer poblaciones permanentes administradas y dirigidas por los nuevos propietarios de las tierras, contando con un ejército hambriento de población española sobrante de las guerras de reconquista y sin acceso a medios de trabajo en la península. Los conquistadores encuentran en las Américas nuevas tierras no para ser trabajadas por los nobles que financiaban o se asociaban a las expediciones sino por las poblaciones nativas y los inmigrantes españoles provenientes de las cárceles y las comunidades más pobres de los campos y las ciudades. La colonización española tendía a reproducir un orden jerárquico donde la Iglesia, los representantes de la monarquía y los propietarios de la tierra ejercieran prácticas de control y administración sobre un sistema en buena medida similar o equivalente al de las castas en el mundo medieval: nobles, sacerdotes y trabajadores de la tierra, pero sin acceso a su propiedad. El sistema anglosajón en cambio, desde el principio marca las características propias de la Modernidad: la Corona Inglesa reconoce la propiedad de la tierra para el que la trabaja, y con ello la posibilidad de cierto grado de independencia económica así como un paradigma implícito de individualismo diferenciado del colectivismo o comunitarismo católico, jesuítico y latino. El comunitarismo anglosajón es de naturaleza estrictamente protestante en las colonias que se establecen tempranamente en el norte de América. Las leyes que regulan la sociedad no pasan por la iglesia institucional sino por la interpretación individual de la Biblia y el apelo a la conciencia, así como una alta valoración de la formación de los niños a través del estudio. $^{2}$

El modelo portugués propició la formación de una elite comercial y una fuerza de trabajo esclava (sistema que duraría hasta fines del siglo XIX, siendo Brasil el último país a abolir la esclavitud). En buena medida, Portugal creó una extraña

\footnotetext{
${ }^{2}$ Es muy sugestivo señalar que una característica de la formación de colonias alemanas protestantes en comunidades rurales del Brasil en el siglo XIX, es la construcción en un mismo local o establecimiento, tanto de una escuela para uso durante los días de semana, como la iglesia para los domingos, siendo imposible reconocer una diferencia física entre ambas funciones, y más aún, el pastor es también el maestro.
} 
¿Qué América es ésta? Sobrevivencias de la colonización europea de Indoamérica, ejemplificando con los casos de Brasil y Argentina

amalgama entre el antiguo régimen esclavista y una minoría poderosa asociada al mercado mercantil y al nuevo mundo capitalista que surgía. En ninguno de ambos modelos (el español y el portugués) se valorizaba el trabajo personal de la tierra, o la dedicación a una incipiente industria que lentamente iba surgiendo para responder a las necesidades regionales y locales de las colonias. La colonización española al menos valoró la creación de las primeras universidades ya en los años de 1500, aún en plena conquista. ${ }^{3}$

La política de la Corona Portuguesa, al contrario, prohibía la creación de universidades, ni tampoco promovía la educación (el poder de la Corona parecía estar asociada a una política deliberada de mantenimiento de un estado de ignorancia para los que emigraban al Brasil, salvo ricos comerciantes o propietarios que debían viajar a Portugal para llegar a formarse, creando así lazos fuertes con Portugal). Tanto es así que la primera universidad en Brasil se crea recién en la primera década del siglo XX y esto representa una rémora enorme para el desarrollo del ciudadano brasileño. Casi cien años pasaron desde la declaración de la independencia en 1822 hasta la inauguración de su primera universidad reconocida oficialmente (en 1934), al contrario de las naciones de colonización española que entre las primeras medidas tomadas por las flamantes autoridades republicanas se halla la creación oficial de universidades y la preocupación por la educación a pesar de las guerras civiles (la Universidad de Buenos Aires por ejemplo, se funda en 1821, apenas 5 años después de la declaración de la independencia, y antes del medio siglo siguiente ya se adopta la política de educación universal). Seguramente ésta es una razón fundamental para entender por qué en el Brasil no surgiera una minoría ilustrada que promoviese las ideas asociadas a la fundación de una república, ni luchas y guerras sanguinarias por la independencia como en el caso de las colonias españolas. ${ }^{4}$ Brasil presenta un

\footnotetext{
${ }^{3}$ En 1538 en el Virreinato del Perú se crea la Universidad Santo Tomás de Aquino, basándose en la bula In Apostolatus Culmine de Paulo III del 28 de octubre de 1538. Y la primera universidad creada y constituida oficialmente por Real Cédula y mandato de la Corona Española es la Universidad de San Marcos en 1551. En Córdoba (actual Argentina) se crea la primera universidad en 1613, y vale la pena observar que en el siglo XX este país llega a adjudicarse casi media docena de Premios Nobel. La mayor "modernidad" de las colonias de España no impide que en la reconquista española de la liberada Cartagena de Indias (en 1810) se vuelva a reinstalar la Inquisición (tan tarde como en 1816), posiblemente como instrumento de control de la Corona.

${ }^{4}$ En el Brasil, los movimientos de independencia tendían a ser locales y surgían de grupos rebeldes focalizados, de comunidades negras de esclavos, indios o colonos disconformes
} 
cuadro de independencia único en América. En primer lugar la presencia de la Corona desde 1808 ya no representa una figura lejana allende el mar sino una corte que se establece en el propio país, una monarquía que tanto política, administrativa e imaginariamente ubica al Brasil como centro del propio imperio. Cuando la Corona se muda al Brasil en ese año, trae consigo ciertas instituciones indispensables para ejercer la administración y el control del propio imperio (como el banco de Portugal). Esta "emigración imperial" se da porque que el rey debe huir de Portugal por miedo a las invasiones napoleónicas y trae su propia corte (y sus cortesanos) que aseguran el traslado de la Corona a la colonia del Brasil. Obviamente, surgen las condiciones para una paradoja que opera no solo sobre los colonos sino también sobre la mente del propio heredero del rey João, Pedro I. Cuando termina el peligro francés y son ahogadas las expectativas revolucionarias y republicanas en Europa, el rey debe volver a Portugal, pero el propio heredero del trono se resiste al retorno, y decide mantener al Brasil como centro del nuevo imperio. La independencia ya no será dolorosa ni violenta como en las colonias españolas. Ésta llega como resultado de un juego de fuerzas e intereses que ponen al príncipe y futuro emperador ante la necesidad de una definición entre los liberales interesados en la independencia y los que apoyan la Corona Portuguesa. Decisión que ofrece finalmente al país una situación privilegiada y un regalo inesperado del propio emperador. Una independencia que llega del propio centro del poder, y no como demanda popular a ser conseguida a través de luchas contra el régimen colonial. Esta Corona transforma a la ex colonia en el centro de un nuevo imperio sin exigir el fin de la monarquía, ni la creación de una república, ni las instituciones que deberían definirla como tal (como es el caso de las ex colonias españolas). El Brasil no sufre una revolución ni guerras nacionales de independencia, las instituciones monárquicas solo exigen sobrevivir al precio de abrir sus puertas y privilegios a sectores autóctonos de elite.

Es importante señalar una diferencia saliente entre las diferentes formas de producción y acumulación de capital en las Américas: mientras la ética protestante sostenía la creación de valor por medio del trabajo, en ninguno de ambos modelos de colonización "latina" en las Américas, la creación de valor se halla legitimada en relación al trabajo o el estudio, sino básicamente a la explotación y

con la política de la Corona en los siglos XVIII y XIX, como en el caso de la llamada Inconfidência Mineira en 1789, una de las primeras rebeliones que asumieron la idea de una república, y a mediados del siglo XIX la guerra Farroupilha en Rio Grande do Sul. 
¿Qué América es ésta? Sobrevivencias de la colonización europea de Indoamérica, ejemplificando con los casos de Brasil y Argentina

la administración centralizada de riquezas naturales, bienes y hombres. El trabajo es considerado de una forma servil y subalterna, y de cierta manera asociada a las representaciones de una condena bíblica.

El tercer tipo de colonización se halla en los países conformados por el dominio de la Corona Inglesa: Canadá, Estados Unidos, y Australia sobre todo. Estos países, como el resto de América, también dependen -al menos en los comienzos de su historia- de su inserción en el mercado mundial y la producción de materias primas a ser reelaboradas en Inglaterra o en algunos casos en otros países europeos. Como los EE. UU. y sus trece colonias son el único de esos países que se independiza de la Corona Inglesa ya en el siglo XVIII, prácticamente la independencia coincide contemporáneamente con la Revolución Industrial. Aún en medio de las luchas por la independencia, se producen discusiones entre los que priorizan una política de protección a la incipiente industria -como Hamilton, el primer oficial del Tesoro- y los estados del sur que prefieren mantener el viejo sistema esclavista de producción asociada a la tierra y la exportación de té y algodón. Hamilton redacta el famoso y clásico Relatorio sobre manufacturas, donde anuncia para el país un futuro donde la industria representaría la base de una economía dinámica opuesta a la visión de una economía agraria de hacendados como pensaba Jefferson. Según su visión, la industria debía constituir la base de la economía, tal como la historia posteriormente demuestra. Dos razones para que las colonias del norte de los Estados Unidos siguieran una política industrialista son por un lado la no existencia de riquezas naturales, ni menos aún la necesidad de instalación de un régimen esclavista y extractivo (como es el caso de las colonias del sur). La segunda razón está en que una enorme masa de inmigrantes europeos emigra en un par de siglos sobre todo a las colonias del norte, donde el acceso a la tierra es prácticamente ilimitado, aunque a costa de la reducción de los territorios indígenas. Y esa nueva y gran masa de población debía ser forzosamente productiva y autosuficiente, ya que su producción no puede volcarse a la exportación sino al crecimiento del propio mercado interno, razón fundamental para entender la inclusión temprana de innovaciones y el uso de maquinaria. La temprana colonización francesa del Québec es contenida en el siglo XVIII por el triunfo de las armas de la Corona Inglesa que ocupa el Canadá con su política expansionista. 
Eduardo A. Vizer - Helenice Carvalho

\section{La independencia y las nuevas naciones americanas}

"Franceses, solo más un esfuerzo, si queréis ser republicanos"

(Marqués de Sade) ${ }^{5}$

Me he referido a tres modelos de colonización en las Américas. Condiciones económicas, políticas, demográficas y culturales de España y Portugal hacen concebir en esos tiempos modalidades diferentes en que se deberá colonizar las nuevas y gigantescas tierras descubiertas en el Nuevo Mundo en función de tradiciones y modalidades ya existentes en cada una de las sociedades de origen. Lo que hay que entender es que estos modelos no resultan de ningún plan racional estratégico de colonización, sino que son la consecuencia histórica, social y cultural de ciertas condiciones y particularidades preexistentes en cada uno de los países colonizadores y sus instituciones, así como luego en las sociedades colonizadas al adquirir su independencia, donde raramente se organizarán esos países de acuerdo a meros planes de sus elites. ${ }^{6} \mathrm{O}$ al menos, éstas deberán tomar muy en consideración las propias limitaciones de esas elites así como las peculiaridades específicas de las sociedades que pretenden gobernar. Donde estas propiedades y características económicas, políticas y culturales no se toman en cuenta, generalmente se producirán conflictos y guerras civiles. Y esto es precisamente lo que sucedió en varios de los países latinoamericanos: interminables guerras civiles movidas por luchas entre diferentes sectores económicos por su predominancia o bien por acciones populares. Un rasgo sobresaliente en estos conflictos se produce por el enfrentamiento entre sectores ligados a la producción tradicional (sobre todo productos de la tierra, textiles y artesanías) y sectores que demandan la apertura comercial y el libre comercio asociado a los puertos, la libre navegación de los ríos interiores y la importación de manufacturas inglesas. Inglaterra a su vez desde el comienzo de las luchas por la independencia comienza a otorgar préstamos financieros que permitan el comercio, al tiempo que se asegura una ligazón de la banca inglesa con las autoridades oficiales y sobre todo con ciertos sectores de las nuevas naciones. El

\footnotetext{
5 Podemos refrasear a Sade: “Americanos, solo un esfuerzo más si queréis ser republicanos".

6 Seguramente, el Brasil presenta una excepción al ser el nuevo emperador Pedro I el que decide no volver a Portugal y asentar su reinado en la colonia del Brasil, con lo que establece una independencia de facto.
} 
¿Qué América es ésta? Sobrevivencias de la colonización europea de Indoamérica, ejemplificando con los casos de Brasil y Argentina

comienzo de una política comercial es también asegurada militarmente por las flotas de Inglaterra y luego Francia.

Volviendo a las condiciones de la colonización (y a las condiciones económicas que se presentan para las nuevas naciones), la existencia o la falta de riquezas naturales determina un modo particular de llevar adelante la colonización y el carácter de las relaciones que se establecen entre la Corona y las sociedades colonizadas. El modelo español establecía la necesidad de instalación humana permanente y la creación de instituciones que sentaran las bases de una nueva sociedad (incluyendo la educación superior), mientras la colonización portuguesa concebía a las colonias bajo la visión de factorías comerciales. Por otro lado, las colonias inglesas, alimentadas permanentemente con la emigración europea de familias (no de conquistadores ni meramente comerciantes o aventureros) concebían América como la "tierra prometida" casi en sentido bíblico, donde el valor central a ser resguardado era la independencia del régimen feudal y la libertad religiosa, asegurando las condiciones necesarias para la supervivencia por medio del acceso abundante a la tierra. En forma paralela a estas circunstancias, la libertad de movimiento y las necesidades de crecimiento económico, incentivaron y favorecieron la iniciativa personal y el acceso a la educación, todo dentro de comunidades que valoraban en alto grado estas características. Como un elemento también paralelo a estos procesos objetivos podemos mencionar las condiciones psicológicas y mentales que se deben desarrollar en los colonos para acompañar estos procesos: por un lado un comienzo algo incipiente de conciencia republicana que se irá afianzando con la guerra de independencia norteamericana y un incentivo a los valores implícitos del individualismo, el que por otro lado ya forma parte de la cultura internalizada del súbdito inglés desde la Edad Media, y evoluciona velozmente con la Revolución Industrial y su "geopolítica" de expansión permanente.

En los nuevos países latinoamericanos, ninguna de estas características socioeconómicas, culturales ni mentales se presentan de la misma forma que en las colonias inglesas. Las condiciones mentales y culturales difieren enormemente entre las mayorías nativas y las clases urbanas, las primeras sujetas a las tradiciones seculares en parte indígenas y en parte producto de una mezcla entre

\footnotetext{
7 A mediados de la década del 1840, estando la Argentina dominada por el caudillo Rosas, federalista y opuesto a la elite unitaria favorable al libre comercio, debe sufrir la invasión de sus ríos por una flota anglofrancesa que exige la libre navegación de los ríos interiores.
} 
aquellas y las de los europeos establecidos en las Américas. A su vez las clases urbanas poseían una identidad latina que las separaba de la identidad nativa y las dejaba fuertemente dependiente de las instituciones sociales, económicas y culturales de "la madre patria" y por consiguiente de una mentalidad monárquica. Una parte de estas poblaciones urbanas, al haber tenido acceso a las universidades hispánicas del Alto Perú, México o Argentina representaban una masa crítica letrada que alimentó intelectualmente las primeras rebeliones exitosas y las consiguientes guerras de independencia a las que las nuevas naciones se debieron enfrentar. En las guerras, esta conciencia republicana se fue también internalizando en las culturas del interior, asimilando, procesando y finalmente asumiendo las nuevas ideas con los valores tradicionales de las culturas nativas. Las nuevas culturas e instituciones republicanas surgidas en las ex colonias españolas absorbían dentro de sí una multiplicidad de tendencias y fuerzas preexistentes, todo lo cual irá expresando y definiendo las particularidades tan propias a las nuevas naciones latinoamericanas. En el Brasil, estos procesos también se presentan, pero a un ritmo y en tiempos diferentes a los del resto de las naciones. La conciencia republicana recién se institucionalizará oficialmente en 1889, y el fin de la esclavitud solo un año antes. El enorme peso de la dependencia económica de la explotación de los recursos naturales de la tierra y el campo y la falta de industrias explican el atraso en reconocer el fin de la esclavitud, de la cual dependía la economía y el comercio nacional, tal como lo había sido en los estados del sur de los Estado Unidos hasta el fin de la Guerra Civil.

Parece que uno de los únicos puntos en común entre las colonias inglesas y las españolas (no así para Brasil), será la necesidad de una (o unas) guerras de independencia. Pero si la guerra de independencia norteamericana favoreció la creación de una conciencia de unidad entre las trece colonias, en América Latina esas guerras produjeron todo lo contrario: una fragmentación que daría origen a una serie de naciones independientes. Esta fragmentación (a la que se opusieron caudillos como Bolívar) se hizo inevitable y creciente con el surgimiento de sectores e intereses particulares y regionales. A su vez, la debilidad y dependencia económica de estas nuevas naciones fue acentuada con las políticas expansivas y las presiones de Inglaterra, Francia y luego los Estados Unidos. Allí se encuentra la matriz original en que se originan las políticas latinoamericanas que marcarán la historia económica y política de estas naciones por dos siglos: la conciencia del atraso, la necesidad de organizar políticas de desarrollo, las fantasías míticas de una nueva independencia y unidad latinoamericana que debería 
¿Qué América es ésta? Sobrevivencias de la colonización europea de Indoamérica,
ejemplificando con los casos de Brasil y Argentina

ser ganada, y al mismo tiempo conciencia de la impotencia y debilidad en que viven estas sociedades. Algunas orientando políticas de extracción de riquezas de la tierra o el subsuelo (como la minería y recursos naturales), y otras que debían crear políticas que desarrollaran nuevas producciones y mercancías que aseguraran el pago de los empréstitos de la banca y el desarrollo del comercio.

Para los países de América que recién se libraban del yugo monárquico y semimedieval heredado de las instituciones españolas y portuguesas, el proceso de construcción de una sociedad (semi)inclusiva, al menos en cuanto a valores culturales, y a instituciones nacionales y estatales reconocidas, lleva varias décadas del siglo XIX y hasta el siglo XX. Las guerras civiles generalmente pasan a formar parte de la historia de la construcción de las nuevas naciones y la legitimación de las instituciones estatales que las constituyen. El proceso varía mucho de país a país, dependiendo de varios factores fundamentalmente demográficos. Los países de población mayoritariamente indígena y homogénea (sobre todo andinos en América del Sur y Central) presentan una sociedad que resguarda sus instituciones tradicionales y se hallan supeditadas a un poder y un control hegemónicos por parte de una minoría blanca. Ésta construye su propia versión de estado, disociado de los sectores nativos, a veces negándolos u oprimiéndolos abiertamente en sentido económico, social y aún cultural. Todavía en el siglo XXI, y luego de varias experiencias como el zapatismo en el sur de México que surge en 1994, y sobre todo en la experiencia boliviana con el presidente Evo Morales, las sociedades nativas comienzan a desenvolver procesos institucionales de gobierno descentralizados que representan a las diferentes etnias locales (o "naciones originarias"), aunque comúnmente surgen procesos políticos que intentan integrar a las sociedades tradicionales y a las clases populares bajo la forma de líderes que cultivan prácticas y discursos marcados por un populismo nacionalista. Aún en Argentina, aunque predominantemente europeizada y con un grado de desarrollo industrial elevado para los patrones latinoamericanos, surge la figura del general Perón y su Partido Justicialista, que sobrevive a lo largo de siete décadas marcadas por gobiernos que cubren casi todo el arco ideológico de la izquierda a la derecha, revelando la existencia de un profundo proceso subyacente de búsqueda de una conformación histórica particular de estado, etiquetado bajo el rótulo de populismo. Hasta cierto punto presenta características algo similares al Partido Revolucionario Institucional de México que logra sobrevivir también siete décadas pero con un marcado acento institucionalista y sin el personalismo recurrente del peronismo. 
Salta a la vista que estas sociedades latinoamericanas no logran conformarse con una ideología e instituciones de corte liberal, tal como sucede en Europa y con las naciones del Commonwealth inglés y los Estados Unidos. A pesar del fuerte institucionalismo liberal instalado con mucho éxito a partir de las cuatro últimas décadas del siglo XIX y prácticamente hasta el fin de la Segunda Guerra Mundial en Argentina y también en el Brasil, solo unos poquísimos casos de democracias latinoamericanas (generalmente en países pequeños como Uruguay, Costa Rica o hasta cierto punto Chile) logran mantenerse inmunes a los vientos de las demandas de gobiernos fuertes y políticas populistas que buscan integrar políticamente a las masas populares como cuadros de un partido gobernante. Algo muy interesante y preocupante debe estar sucediendo por debajo de la superficie de estas sociedades. Podríamos señalar como un síntoma evidente, las demandas que presentan las grandes masas populares por no llegar a ser genuinamente representadas en el sistema político. Y ésta es una constante prácticamente en cualquiera de los países latinoamericanos. Los partidos de izquierda tienen un discurso altamente racionalizado que brinda explicaciones clasistas y económicas adecuadas, pero estos discursos (a diferencia de Europa) raramente llegan a ser asimilados por las masas populares, y si lo hacen, generalmente son el producto de adaptaciones nativas y compromisos políticos y económicos que limitan su eficacia y su campo de acción. Existe un poderoso argumento tanto racional como emocional que galvaniza a las masas: la desigualdad y la injusticia social, política y económica. Especialmente en el Brasil la desigualdad ubica al país entre los más desiguales, junto a Sudáfrica y el Oriente Medio. Estos argumentos alimentan discursos que regularmente enfervorizan hasta a sectores descontentos de las clases medias que demandan justicia, representación e integración social y política. Podemos señalar como un ejemplo de efectiva síntesis doctrinaria a las banderas del peronismo: "constituir una Nación socialmente justa, económicamente libre y políticamente soberana". La gran cuestión por detrás de los discursos y la historia oficial es si el sistema democrático y las instituciones liberales latinoamericanas son capaces de presentar respuestas adecuadas a estas demandas que hoy en el siglo XXI se han hecho universales.

El populismo en su expresión latinoamericana representaría una modalidad reactiva, un apelo al sentimiento, al afecto que los discursos "racionales" de políticos conservadores o liberales -comúnmente marcados con argumentos sobre imperativos económicos y una valoración implícita o explícita a la necesidad de racionalidad económica- no logran despertar en los públicos que 
¿Qué América es ésta? Sobrevivencias de la colonización europea de Indoamérica, ejemplificando con los casos de Brasil y Argentina

demandan más trabajo, mas justicia, mejor distribución de la renta. En otras palabras, las masas populares precisan sentir una identificación emocional con el gobernante, y además sentirse representadas, escuchadas y atendidas en sus demandas de reconocimiento y "afecto" por parte de figuras políticas fuertes ${ }^{8}$, exigiendo implícitamente un gobierno generalmente personalista cuya característica saliente sería un estado presidencialista que se propone activamente ir "a la búsqueda de su sociedad", la integración social en la forma de un gobierno que interpela activamente a sectores específicos de la sociedad en detrimento del resto de los ciudadanos, en otras palabras, no un gobierno representativo de todos y para todos, sino de un sector para otros sectores específicos. Este tipo de estado generalmente caracterizó buena parte de la historia latinoamericana ${ }^{9}$, salvo períodos de revoluciones, de dictaduras de duración incierta, o de interregnos de gobiernos democráticos generalmente institucionales pero sujetos a condicionamientos militares o crisis económicas paralizantes.

Podemos someramente interpretar la historia de los países latinoamericanos a partir de su independencia hace ya dos siglos atrás, como sociedades que se hallan a la búsqueda de la construcción de un estado, proceso que comienza con la independencia de la Corona Española y prosigue con diferentes experiencias y altibajos hasta el presente siglo XXI. Podemos proponer la siguiente tesis: las nuevas naciones latinoamericanas, al renegar del estado monárquico español, al descubrirse a sí mismas como nuevas sociedades poscoloniales aún sin instituciones de estado establecidas y reconocidas, se hallaron en una dramática y permanente búsqueda por la construcción de nuevas formas institucionales, siempre bajo la supervisión y las demandas permanentes de sectores sociales que exigen ser reconocidos y representados en sus derechos. En el Brasil la relación históricamente se invierte: cuando el emperador Pedro I declara al Brasil independiente de Portugal, Pedro mantiene la corona - o sea el símbolo del estadoen el propio país. Con esto, desarma las fuerzas explosivas del republicanismo

\footnotetext{
${ }^{8}$ Históricamente, surgen en forma inmediata ejemplos conocidos mundialmente: la figura paternalista y acogedora de Lula en Brasil durante sus dos gobiernos, y la figura de Perón en Argentina, como un militar que representaría en sí mismo tanto las figuras de un discurso político de "orden" y un apelo al afecto y el nacionalismo.

${ }_{9}$ Aunque parece que desde el triunfo de Trump en los Estados Unidos en el 2016 el populismo ha dejado de ser una casi exclusividad latinoamericana. Y las experiencias neonacionalistas europeas luego del triunfo del empresario republicano han visto reforzadas las actitudes y tendencias de los partidos populistas en Europa.
} 
triunfante en las Américas, pero al costo de dejar al propio pueblo en condición de invisibilidad y pasividad. Se inaugura prácticamente un estado brasileño sin sociedad, o más bien, un estado para sí mismo sin otra representatividad que una forma institucional vacía de contenido, un estado sin pueblo. Representa así la contracara de las nuevas naciones hispanas de América, independientes de la Corona pero huérfanas de un estado. El republicanismo se transforma en la fuerza ideológica que moverá la historia de estos países en el siglo XIX. Un republicanismo alimentado por los antecedentes exitosos de la revolución americana y la francesa, las cuales servirán de referencia poderosa para varias generaciones de políticos e intelectuales hispanoamericanos. Las cadenas de la secular monarquía opresiva de España, se rompen con la participación ferviente de nativos pobres, negros liberados de la esclavitud y criollos que toman las armas en las luchas por la Independencia prácticamente en toda América del Sur y Central. Ese pueblo (mal llamado "latino") se transforma en el nuevo actor político hispanoamericano.

Este proceso de republicanismo -y modernización- latinoamericano recién comienza a desarrollarse plenamente en el Brasil prácticamente en las últimas décadas del siglo XIX, al decretar la princesa Isabel la Ley Aurea y el fin de la esclavitud (la población negra constituía el 30\% de la total a comienzos del siglo XIX, y representaba un peligro para la Corona con el ejemplo de la revolución haitiana de esclavos que se remonta ya a 1804, incendiando las mentes con imágenes de revueltas, levantamientos y la creación de las comunidades de esclavos que huyen para vivir en comunidades denominadas "quilombolas"). Con la tardía declaración de la república en 1889, estos antecedentes presentan al Brasil como el único país de América donde los títulos de nobleza aún serían merecedores de un rango de honor, un signo de distinción social. Podemos parafrasear al héroe cubano José Martí, cuando en Nuestra América se habla de las continuidades de la colonia en la república, la secuela de la esclavitud siguió viviendo en la república. ${ }^{10}$ Un tipo de sociedad multiétnica se ha ido formando sobre todo en los países donde el esclavismo africano fue instalado de manera forzada, determinando una conformación social de identidades múltiples,

\footnotetext{
${ }^{10}$ Es importante reconocer que Brasil fue el primer país del mundo que en 1995 reconoció la existencia del trabajo esclavo. Sin embargo, entre 1996 y 2014, casi 49.000 trabajadores esclavos han sido liberados. La fiscalización del estado ha detectado la presencia de trabajadores en condiciones precarias, alojados en barracones con techo de plástico y paja, los que dormían sobre el suelo, sin baño y sin acceso al agua potable.
} 
¿Qué América es ésta? Sobrevivencias de la colonización europea de Indoamérica, ejemplificando con los casos de Brasil y Argentina

gobernada exclusivamente por una minoría blanca, y definiendo una división profunda entre el estado y la sociedad, casi siempre marcada por prácticas y una cultura de segregación manifiesta y que permanece aun hoy en día. La pobreza extrema y la marginalidad se manifiestan en todos los sentidos, y cobra su expresión más objetiva en la segregación espacial en las ciudades, en la permanencia de las favelas y las villas miseria. Otro rasgo que parece sobrevivir de un pasado colonial secular es una falencia extrema de sentido de ciudadanía, la falta de la presencia del estado como institución activa e inclusiva en la sociedad. Para el ciudadano pobre el estado está -siempre estuvo- ausente, o presente solo a través de prácticas represivas, tumultos o amenazas al orden establecido. Se manifiestan conductas asociadas a la anarquía gobernando las instituciones, desde la unidad familiar hasta las políticas de estado -o la falta de ellas-. Hemos denominado esta situación como "síndrome de abandono", como orfandad y expresión de anomia social. Las instituciones actúan según su libre albedrío, como estando fuera de un orden social que les exige cumplir un rol, una exigencia social que es la razón para su propia existencia, una función que requiere conciencia del deber hacia los otros y al país, de acuerdo con un contrato de cumplimiento implícito de obligaciones acorde a los medios que el propio estado les provee para cumplir con aquellas. Las instituciones parecen operar como si cumplieran efectivamente su papel, y el estado como si efectivamente vigilara el cumplimiento de ese contrato social. Los niños dejan de ir a la escuela, los maestros se conducen como si los alumnos realmente aprendiesen, y los padres se conforman con una mera presencia poco comprometida de los hijos en la escuela. La característica sobresaliente es una anomia que corroe al estado, a la política y a las instituciones que deberían regular el funcionamiento de la sociedad, a las familias y -tal vez lo más riesgoso y peor de todo- a las nuevas generaciones de niños que crecen con una orfandad de referencias y valores sólidos y sin perspectivas de futuro. Prácticamente toda América Latina se halla en esta encrucijada que tiende a condenarla a un futuro incierto y a rumbos imprecisos. ${ }^{11}$

${ }^{11} \mathrm{El}$ periodista D. Mainardi hace un juicio feroz del Brasil en la revista Veja del 22/10/2003: "Hay un atavismo esclavócrata. Los señores de esclavos se comportaban como bien entendían, y sus dependientes eran obligados a fingir que no veían nada [...] Si el Brasil quisiera aprender a lidiar con autoridades, precisa recordar que no es una nación de esclavos, sino de bastardos, de hijos ilegítimos [...]. Por eso debemos saber cómo se comportan nuestros políticos [...] para que ellos no se sientan libres para actuar como nuestros señores. Ellos son tan bastardos como nosotros". El juicio del periodista es 
Volviendo a nuestro análisis comparativo entre países y colonizaciones diferentes, podemos mencionar también a un tipo de sociedad latinoamericana que ha surgido históricamente donde una población escasa fue conmovida por procesos de inmigración masiva, generalmente europea (española, italiana, portuguesa, alemana, inglesa, árabe y centroeuropea). Los casos más típicos se hallan en Uruguay y Argentina, y en menor grado Brasil y Chile. En Argentina todo el siglo XIX está marcado por la presencia y la preocupación por el desierto, la pampa, el gaucho y la falta de población que asegure las fronteras, sobre todo frente a los avances y la creciente población del Brasil. ${ }^{12}$ Este país presenta seguramente uno de los ejemplos más diversos de multietnia, reuniendo todos los tipos étnicos mencionados hasta ahora: negros, indios, portugueses y europeos de diversas nacionalidades. Argentina, al igual que Uruguay presentan características étnicas similares, aunque sin la presencia africana y reemplazando portugueses por españoles (así, por ejemplo, los negros han prestado aportes sumamente enriquecedores a la música latinoamericana además de la norteamericana). En los países del Cono Sur, la identidad nacional presenta rasgos que denotan en su población rasgos que remiten a Europa, llevando a representaciones de la propia identidad como europeos transplantados o europeos que han descendido de los barcos que los traían de Europa (así definen humorísticamente muchos argentinos la ascendencia europea que define a un porcentaje relevante de su población). Las inmigraciones internas y de los países limítrofes han logrado diluir paulatinamente esta imaginaria hegemonía de la presencia europea, ahora algo obscurecida hasta en la propia piel de argentinos, uruguayos, chilenos y brasileños de los estados del sur. La cuestión de la identidad nacional se ha transformado en un complejo cultural que ha marcado el arte, la cultura y

seguramente exagerado, aún en esos años, pero el gran proceso judicial que marca al país desde 2014 pone en el banquillo de los acusados por corrupción a la gran mayoría de la clase política gobernante y a algunas de las mayores empresas del país. Por otro lado, en la Argentina el escenario político, si bien no llega a las dimensiones catastróficas del Brasil, tampoco presenta un cuadro político aceptable para un país que se considera a sí mismo más cercano a las normas republicanas y democráticas.

${ }^{12}$ En Argentina aún sigue presente la preocupación por poblar el desierto, y poblar la Patagonia, pero si el proyecto original del siglo XIX contemplaba atraer la inmigración europea del norte - con baja tasa de natalidad - el siglo XXI muestra una fuerte presencia de inmigración de los países vecinos, en especial los más castigados por la pobreza. El historiador argentino Tulio Halperín Donghi, al hablar sobre la preocupación argentina por el desierto y la falta de población, escribe Una nación para el desierto argentino (1982). 
¿Qué América es ésta? Sobrevivencias de la colonización europea de Indoamérica, ejemplificando con los casos de Brasil y Argentina

la intelectualidad latinoamericana (Jorge Luis Borges seguramente representa en su literatura un ejemplo sobresaliente de esta crisis de identidad, donde el argentino suele pensarse y reflejarse a sí mismo en los espejos distorsionados de una literatura inglesa o francesa).

\section{Mundo privado y mundo público. ¿Hay relación con el desarrollo económico y la modernización?}

El régimen de gobierno republicano tiene como una de sus propiedades centrales por un lado la creación y el reconocimiento de una separación tajante entre el mundo privado y el público, el espacio privado y el espacio público. Durante tres largos siglos de colonialismo monárquico español y portugués en América Latina, se crearon para la población instituciones, leyes y valores de una cultura que promovía la apropiación prácticamente privada de los bienes y el espacio -y hasta de personas- por parte de los monarcas y hombres poderosos. En las colonias inglesas este carácter privado de apropiación se hallaba estrictamente limitado y constreñido por varios siglos de reconocimiento de una separación legal entre la sociedad en tanto conjunto de individuos y la monarquía, y por otra parte el reconocimiento de ciertos derechos públicos de sectores medios y de la baja nobleza, (los barones ingleses exigen en 1215 la limitación del poder absoluto del rey y la iglesia), y así sus derechos son reconocidos ya en la Carta Magna desde el siglo XII. Las monarquías absolutistas ibéricas, a pesar de rebeliones y experiencias de afirmación y reconocimiento por parte de algunos sectores medios en el siglo XIX, no llegaron a institucionalizar una separación clara entre los derechos monárquicos y los de los emergentes sectores medios y burgueses asociados al comercio y una aún incipiente industria. En las colonias, esta pesada herencia opresiva no se manifestaba solo en las instituciones sino también en la cultura y la formación de los valores y las creencias de toda la sociedad, moldeando las formas subjetivas de construcción de las representaciones sobre la propia sociedad, las instituciones, el individuo y las formas de gobierno tradicionales. El ejercicio del poder como una propiedad individual del monarca y no una práctica institucional y pública, fue considerado un atributo prácticamente natural y universal, en especial en las colonias portuguesas, donde los ideales republicanos solo se expresan muy tardíamente en el siglo XIX. Esto al contrario de las naciones hispanoparlantes donde las guerras de independencia, la prensa de la primera y segunda décadas del siglo y los escritos de líderes revolucionarios o independentistas crearon las condiciones tanto 
objetivas como subjetivas para hacer emerger paulatinamente una conciencia del reconocimiento de una ciudadanía con derechos individuales, públicos y republicanos.

En el caso de Brasil, este proceso de modernización institucional y cultural a pesar del reconocimiento de la elite decimonónica a la filosofía positivista (la bandera brasileña tiene inscrito el lema "Ordem e Progresso") se vio obstaculizado por la supervivencia y la aceptación de la monarquía como un régimen de gobierno por un lado válido y sobre todo reconocido por el establishment de los países europeos, y por el otro como un valor tradicional de prestigio y ascenso social, no por el esfuerzo y el trabajo innovador del individuo como profesional, comerciante o industrial sino como una posibilidad de acceso a un sector social privilegiado y premiado con títulos de nobleza. De este modo, los derechos de un individuo se hallaban directamente asentados no en sus logros personales sino en relación con su posición social, o sea por "sobre" los demás miembros de la sociedad. Una especie de ciudadanía honorífica, donde el ejercicio del poder se transforma en un derecho personal sobre personas y bienes. Lógicamente, la dependencia económica y las exportaciones del país dependían de la producción asentada en el campo, en la mineria y la tierra y obviamente todo el sistema del régimen se sustentaba en el régimen esclavócrata. El derecho individual se asentaba en el poder sobre la propiedad de tierras, esclavos y bienes. El reconocimiento de los derechos (y obligaciones) públicas, prácticamente se hallaba presente en las representaciones sociales de las minorías mayormente de inmigrantes (sobre todo italianos, alemanes y japoneses) asentados en las mayores ciudades, en especial en San Pablo. Todavía en pleno siglo XXI sobreviven estas formaciones y actitudes, a partir de creencias sobre el ejercicio del poder como un derecho individual inmanente de los actores políticos, introyectado en los políticos tradicionales y el ejercicio del gobierno, y en cierta medida sustentada en los medios de comunicación conservadores. También se hace patente en las políticas brasileras de salarios y de ingreso a la función pública, en los organismos de gobierno y en un implícito reconocimiento especial a los miembros de una casta de funcionarios que acceden a un fuero privilegiado que de manera manifiesta y discursivamente sirven al estado, pero en sus prácticas y culturas institucionales operan implícitamente en beneficio personal. El espacio público aún no está sólidamente reconocido como una institución y un derecho claramente establecido para todos los sectores sociales y las expresiones culturales y políticas de la sociedad. El espacio y el orden privados se introducen abierta o sorrateramente en cada práctica 
¿Qué América es ésta? Sobrevivencias de la colonización europea de Indoamérica, ejemplificando con los casos de Brasil y Argentina

institucional y en el ejercicio de la vida pública cotidiana. Esto se traduce a una diversidad de prácticas que lindan o se hallan abiertamente asociadas a formas de corrupción y un consiguiente apelo a la impunidad, lo que para ciertos sectores privilegiados fácilmente se traduce a la figura del "fuero privilegiado" al que acceden legalmente funcionarios políticos, y en manera a veces explícita y otras latente, los jueces, militares y otros personajes públicos. Podemos considerarla genéricamente una "corte civil patrimonialista".

Argentina también presenta un caso especial de relaciones históricas entre su sociedad y la formación del estado. Le llevó medio siglo (entre la Independencia en 1810 hasta 1860) superar las guerras civiles y conformar un estado con todas las propiedades de la modernidad. Es sumamente sugestivo el título que un gran maestro y presidente de Argentina le dio a su libro más famoso: Civilización y barbarie. Esta última metaforiza el desierto mínimamente poblado del nuevo país, no solo sin gente, sino sin "cultura" ni progreso material y cultural, llegando al extremo de sugerir que "la sangre del gaucho solo sirve para regar la tierra". Cuando llega a ser presidente a mediados de 1860, Sarmiento pone en práctica su plan de educación universal y de colonización. Esperando una inmigración masiva de pueblos nórdicos y sobre todo anglosajones, se lamenta luego de que solo llegan italianos y españoles casi sin instrucción alguna, cuyos hijos deberán pasar por la escuela pública y sin las instituciones que tanto admiraba en la colonización anglosajona norteamericana. La civilización que se iba formando no era la importada de Europa sino el resultado de un proceso de mezcla de pueblos y razas diversas. Aunque el argentino y el uruguayo aún hoy gustan erróneamente definirse como europeos transplantados. Algo similar se da también en algunos estados del sur de Brasil y de Chile, que también recibieron numerosa inmigración europea.

Los países "castellanos" del Cono Sur de América presentan el ejemplo más acabado de instituciones modernas, en algunos casos de manera más rotunda que en las monarquías europeas del siglo XIX. Si en Europa (en especial en Alemania y el Imperio Austrohúngaro, monárquicos hasta el final de la Primera Guerra Mundial) el conflicto se presenta entre las elites monárquicas y las aspiraciones políticas de una pujante burguesía industrialista, en los Estados Unidos esta burguesía todopoderosa es inseparable de la conformación histórica, social e institucional de los estados del norte de América del Norte. Esto hasta el punto de promover una terrible guerra civil para imponerse sobre los estados del sur y así instalar una sociedad capitalista más moderna, sin rémoras 
del régimen esclavista y más adecuado a las condiciones que impone el desarrollo de las relaciones sociales y económicas en el capitalismo industrial. En el resto de las Américas, la propia demografía y la cultura de los pueblos de ambas Américas se hallaba en "otro mundo", donde el capitalismo solo podía representar a pequeñas minorías urbanas dentro de un océano de culturas tradicionales. Esas minorías han surgido y se han fortalecido en función de intereses fuertemente ligados al mercado mundial y a la producción de mercancías agrícolas o de materias primas destinadas a la exportación. El conflicto se planteaba entre estas minorías urbanas (que en la primera mitad del siglo XIX se autodenominaban "unitarias" en la Argentina) y las mayorías rurales del interior (autodenominadas "federales"). Para Sarmiento, el antagonismo entre "civilización y barbarie" parecía más que evidente. El primer término definía las características de un país y un estado moderno, mientras el segundo representaba el atraso. El atraso del interior preindustrial, del campo y del liderazgo de figuras caudillescas autóctonas, casi siempre resistiéndose a la pujanza de la modernidad urbana liderada por élites volcadas a las relaciones comerciales sobre todo con Inglaterra. Esos liderazgos generalmente no representaban solamente la defensa de la tradición y los intereses nacionales, sino el mantenimiento y el control sobre las estructuras productivas, relaciones sociales e intereses económicos regionales o locales. A pesar del republicanismo declarado, el espacio público es vivido como una extensión del espacio y el mundo privado, signado por los afectos y la tradición y no por la letra escrita de leyes e instituciones impersonales, generalmente importadas y trasplantadas de Europa o los Estados Unidos por una elite intelectual informada, pero divorciada de las mayorías y del mundo popular, el que se supone deberá ser institucionalizado y organizado en base a leyes.

Los criterios que definen a la civilización sarmientina se oponen diametralmente a los criterios y las relaciones culturales y sociales de las poblaciones del interior. Mientras éstas expresan el particularismo de las tradiciones locales, la civilización expresa universalismo y cosmopolitismo, el progreso social y político, la separación estricta entre el mundo privado y el público, la razón por sobre la tradición y los afectos, las instituciones de la ley como ordenadores máximos del orden social y político. Un aspecto fundamental de los cambios a instalar en el cuerpo social se revela en los valores de una nueva subjetividad que valoriza sobre todo al individualismo (burgués) por sobre una subjetividad cimentada en valores tradicionales y en los valores sociales y religiosos de la vida en comunidad. Seguramente, la figura del gaucho (el Martín Fierro de la literatura gauchesca) repre- 
¿Qué América es ésta? Sobrevivencias de la colonización europea de Indoamérica, ejemplificando con los casos de Brasil y Argentina

senta un modelo marginal alejado de lo comunitario, ya que asienta su modo de vida y sus valores en la búsqueda de la libertad personal y la independencia de movimiento, montado en su caballo y atravesando campos y desiertos interminables de una Argentina aún mínimamente poblada, y rechazando tanto a la tradición de las comunidades rurales, como a las imposiciones del estado y sus instituciones, incluyendo a la vida urbana y la ciudad. La marginación del gaucho, tanto de las comunidades rurales como urbanas de la Argentina, del Uruguay y del sur del Brasil representa un ícono cultural e identitario que se aleja tanto del paradigma clásico de las sociedades nativas americanas como de la influencia avasalladora de la modernidad que se va asentando en las ciudades y en las nuevas comunidades de inmigrantes sobre todo europeas, japonesas en São Paulo y en mucho menor medida árabes en el noroeste de Argentina y en el centro sur del Brasil. La independencia del gaucho no tiene ninguna relación con el individualismo que se desarrolla en las ciudades y que presenta una curiosa ambigüedad: para cultivar ese individualismo el ciudadano de los siglos XIX y XX requiere también de la independencia personal y al acceso a medios e instituciones que permitan su desarrollo, pero éste solo será posible en base a la coexistencia con los condicionamientos de la vida social urbana y una comunidad donde pudiesen cultivarse posibilidades de afirmación y crecimiento personal. Curiosa ambigüedad burguesa de las Américas.

En las últimas décadas del siglo XIX y sobre todo en las primeras del siguiente siglo, se va imponiendo la conciencia de la necesidad de un desarrollo industrial tardío pero absolutamente necesario, en especial a partir de la Primera y la Segunda Guerra Mundial donde se cierra la importación de productos manufacturados imprescindibles. La nueva mano de obra para esta industrialización surge precisamente del interior, del campo, de las supervivencias del viejo orden bárbaro que debía aprender por las buenas o por las malas a trabajar en las condiciones insalubres de las fábricas y los suburbios de las ciudades. Una minoría de trabajadores inmigrantes (sobre todo italianos y españoles) se armaba ideológicamente con los principios del anarquismo y del socialismo importados de Europa. Pero la gran masa de trabajadores nativos no se identificaba con estas ideas ni sus formas de acción y organización, conformando lo que podemos llamar de población potencialmente vacía de modelos prospectivos de futuro, e ideológicamente disponibles para otras formas de encuadramiento social y político. Esta disponibilidad social y cultural halla generalmente su encuadramiento político con la aparición de figuras carismáticas fuertemente populares y populistas en su discurso. Seguramente uno de los ejemplos históricos más 
relevantes aparece con la Revolución Mexicana de comienzos del siglo XX, de carácter popular y antifeudal, finalmente encuadrados en la figura del Partido Revolucionario Institucional (PRI), el que gobierna México por largos 70 años. Tomando nuevamente el caso argentino, en 1945 con el fin de la Segunda Guerra Mundial surge un coronel del ejército que hábilmente logra convocar en sí mismo todas las demandas populares aun no expresadas claramente en un discurso doctrinario y en las prácticas de organización política y gremial que marcarán la Argentina indeleblemente por largas décadas, mucho más allá del tercer y corto gobierno peronista (por la muerte del entonces general Perón).

Un peronista tradicional refrasea unas definiciones de Perón que parecen reunir en una fórmula concisa la esencia de este movimiento: "El General decía que la doctrina es lo permanente (la justicia social, la independencia económica y la soberanía política) y la ideología es la montura para cabalgar cada época”. Y luego abunda en críticas sobre una u otra fórmula partidaria que busca entrar en el juego de la política electoral: "Tal o cual agrupación electoral peronista es la peor montura para este tiempo". Vale la pena referirse brevemente a las metáforas atribuidas a Perón. Por un lado hay una fuerte referencia a valores sociales permanentes y fundamentales para cualquier sociedad: justicia social, independencia económica y soberanía política, entendidas como una doctrina que sintetiza ideas fuerza permanentes (y ahistóricas). Por el otro una referencia al cambio histórico y un orden conceptual de ideas guía que ordenan el pensamiento y organizan el sentido: la ideología opera como una "montura" sobre el momento y las circunstancias históricas. Pero en la práctica, el partido se transforma en una mera maquinaria que va más allá del electoralismo, es una máquina de poder en sí mismo. Una máquina verticalista basada en la obediencia a la figura del momento, guardando así reminiscencias del orden militar, tal como el propio Perón organizó al partido a mediados de la década del cuarenta.

A partir de la Revolución Cubana, y posteriormente con el ejemplo de Venezuela, muchos en Latinoamérica volcaron sus inquietudes y esperanzas en hallar en el modelo cubano, un ejemplo finalmente exitoso de organización de la sociedad eliminando las injusticias, la pobreza y la inequidad que frustraba el acceso a mejores condiciones de vida y a las posibilidades de un desarrollo económico y social siempre buscados y siempre truncos, como un espejismo inalcanzable. Pero las últimas décadas mostraron que este modelo cubano también se mostraba como otro espejismo que exigía un costo humano y una pérdida de libertad individual que se mostraba opuesto a los deseos y la tradición que marcó dos 
¿Qué América es ésta? Sobrevivencias de la colonización europea de Indoamérica, ejemplificando con los casos de Brasil y Argentina

siglos de historia latinoamericana. Tampoco se puede olvidar que fue precisamente la revolución cubana la que dio origen -como reacción de las fuerzas más reaccionarias en cada país y de la superpotencia norteamericana- a la peor etapa de la historia de Latinoamérica en cuanto a represión y dictaduras irrestrictas. Todos estos procesos interligados dieron a su vez mayor madurez a una conciencia de las necesidades de hallar y defender un orden social e instituciones más democráticas y opuestas a toda forma de opresión. Desde fines del siglo XX, nuevos aires democratizantes que llegan de todo el mundo, crean alguna esperanza realista en que se pueda conseguir la instalación de instituciones más sólidas y legítimas no solo en el discurso sino en la práctica política y económica. El fundamentalismo neoliberal instalado como política oficial desde el mundo anglosajón en las dos últimas décadas del siglo XX también ha entrado en una profunda crisis que marca sus falencias y peligrosas tendencias antidemocráticas (concentración del poder político y del capital, e inequidades crecientes que erosionan los valores aceptados como democráticos).

Hay indicadores sociales, culturales e institucionales bastante sólidos que ahora se asumen no solo en el discurso oficial de múltiples gobiernos sino también en las prácticas cotidianas, como la igualdad de derechos para todo ciudadano latinoamericano, sin importar su origen, raza o etnia. Este es un avance y una condición indispensable para que las sociedades multiculturales no solo puedan integrar y conservar sus rasgos y características identitarias, tanto indoamericanas de origen como las provenientes de 500 años de colonización europea como africana. Cada vez se considera más indispensable promover políticas de inclusión integral de todas las comunidades que viven en nuestros países, cualquiera sea su origen: europeo, indoamericano, africano o asiático.

\section{Unas palabras sobre la lengua y la comunicación}

En la conquista de las Américas, la lengua fue también un campo de batalla, además de constituir el mayor legado que sobrevive de tres siglos de conquista y dominio europeo. Los tres mayores países conquistadores (España, Portugal e Inglaterra) no solo impusieron su idioma a la fuerza, sino que intentaron en lo posible eliminar todo vestigio de las lenguas originarias de América. El conquistador no puede aceptar el vacío de poder, ni hallarse en la situación de la imposibilidad de entender de qué están hablando los súbditos o que podrían estar tramando. Es siempre un riesgo que una mayoría sometida sea capaz de 
comunicarse, resistir y tal vez organizarse fuera de los dominios de conocimiento y control del conquistador. Los pueblos originarios se vieron forzados a aprender el castellano, el portugués o el inglés, según el área geográfica en que se encontraban. Como las más desarrolladas, extendidas y numerosas poblaciones se hallaban bajo dominio de España (sobre todo el Imperio Inca desde el Perú hasta las regiones adyacentes y el azteca en México) los mayores éxitos militares así como las riquezas a ser explotadas o robadas también provenían de esos dos centros. La conquista de esos imperios requería organizar las poblaciones para el trabajo de explotación sobre todo de las minas, los bosques y la tierra. El disciplinamiento de estos pueblos requería primeramente el aprendizaje del castellano y el obvio desplazamiento y eliminación del derecho de los nuevos súbditos a comunicarse entre ellos en sus idiomas de origen, o que cultivasen rituales religiosos y costumbres no cristianas. Obviamente se debe entender que la lengua y la cultura en todas sus expresiones autóctonas, debían no solo sufrir la represión sino sobrevivir dentro de un campo de batalla cultural simbólico que en muchos aspectos -manifiestos o velados- perdura aún en el presente siglo XXI. Hace solamente unos pocos años atrás que los gobiernos han promovido o reconocido la escuela bilingüe o los sistemas de cuotas especiales para facilitar condiciones de ingreso a la universidad por parte de minorías indígenas. El Paraguay y en parte el nordeste argentino tienen una predominancia del idioma guaraní, Bolivia tiene una absoluta mayoría de hablantes del quechua y del aymará y ambos países constituyen una excepción en el cuadro lingüístico de Sudamérica.

En este sentido, se debe reconocer que tanto el castellano como el portugués, al menos han favorecido un escenario de cierta homogeneidad identitaria para nuestros países. Como contraejemplo, Europa a lo largo de veinte siglos solo ha conseguido fraccionar aún más (o mantener exitosamente, según el punto de vista) el escenario lingüístico y cultural: cada país mantiene y cultiva con orgullo su idioma original, a pesar de los intentos hegemónicos de la Corona Inglesa en el Reino Unido por imponer el inglés (en especial en Irlanda); o AustriaHungría con el alemán y el húngaro en el centro de Europa, y España con el castellano en Cataluña y Vasconia. En Europa, ha sido precisamente la lucha por imponer o bien mantener el idioma de origen el que ha dado pie y pretextos para innúmeras guerras y nacionalismos diversos a lo largo de toda su historia (algunos nacionalismos abiertamente xenófobos, racistas y belicosos como el nacionalsocialismo). En las Américas el siglo XX en este sentido ha favorecido no solo una mejor coexistencia entre idiomas y culturas, sino ofrecido un efecto 
¿Qué América es ésta? Sobrevivencias de la colonización europea de Indoamérica, ejemplificando con los casos de Brasil y Argentina

positivo para la convivencia y el reconocimiento entre culturas diferentes, compartiendo tres siglos de resistencia primero violenta al conquistador, y luego relativamente pacífica con las instituciones de la modernidad. Dentro de su diversidad identitaria, y a pesar de algunas pocas guerras regionales, los países de América en este sentido pueden aún brindar uno de los mejores ejemplos de convivencia pacífica. La supervivencia lingüística de la conquista constituye hoy una herencia y un aporte invaluable para la construcción de una América no solo pacífica sino culturalmente creativa y democrática.

\section{Epílogo}

Cuando este trabajo estaba terminado pero aún no enviado a publicación, las críticas condiciones de la crisis política y económica en Brasil (muchos la consideran la peor de su historia) se recrudecen con el discurso de un general en una reunión masónica multitudinaria -luego apoyado por la plana mayor del ejército- donde declara abiertamente "si los tribunales del proceso Lava Jato que están acusando y juzgando a políticos corruptos del poder legislativo y el ejecutivo no apartan a estos sujetos de sus cargos (incluyendo al presidente de la nación), lo harán las fuerzas armadas". La gravedad de la situación se halla aún más recalcada por el discurso de un senador en el Parlamento, donde anuncia que en el caso de que el poder judicial no realice una condena que es demandada por buena parte de los brasileños, las fuerzas armadas de los Estados Unidos intervendrán en el país (luego el propio senador denuncia que el discurso era falso). La dramática gravedad de la situación representa un ejemplo casi típico y repetido en la historia latinoamericana ( $y$ en el propio Brasil), pero esta vez en uno de los países más desiguales del mundo, donde las instituciones entran en un conflicto explosivo entre sí, y donde la mayor parte de la población prácticamente permanece como mero observadora. La crisis pone de manifiesto la mínima legitimidad y reconocimiento de la representatividad y efectividad de las instituciones republicanas y democráticas para el grueso del pueblo.

El sentido del bien colectivo y de lo público se halla en plena crisis (tal vez nunca estuvo realmente establecido en la conciencia social). En el Brasil esto se observa, por ejemplo, en el hecho de que las manifestaciones de protesta popular tienden permanentemente a terminar con una quema generalizada del transporte público, que es un servicio público indispensable y de uso mayoritario por 
los más pobres, y no de las clases medias brasileras que tienden a rechazar medios de transporte público.

Lamentablemente, esta crisis a mediados de la segunda década del siglo XXI, se torna representativa para los argumentos que hemos presentado aquí, en especial sobre que una mayoría de las sociedades de Latinoamérica aún se encuentran a la búsqueda de la construcción de su propio estado. La mayoría de los gobiernos tradicionalmente se hallan disociados de la sociedad, y gobernando para una minoría. Cuando algún gobierno intenta (demagógicamente o no) introducir mayor justicia y representatividad popular, se transforma en blanco de los intereses y las peores críticas, tanto a nivel interno como externo. El conflicto se instala en todos los ámbitos, y la corrupción estructural que los medios de comunicación habían mantenido en sordina aflora como argumento de guerra y justificación de los fracasos de una democracia manifiestamente formal. Las puertas se abren dramáticamente para los aventureros y "los salvadores de la patria".

\section{Bibliografía}

Barroso, Luís Roberto. 2017. Carta Capital, 16 de agosto de 2017. 13.

Devoto, Fernando. 2011. La Historiografía académica y la Historiografía militante en Argentina y Uruguay. Buenos Aires: Biblos.

Devoto, Fausto. 2008. Argentina Brasil, 1850-2000. Un ensayo de historia comparada. Buenos Aires: Sudamericana.

Marley, David. 1998. Wars of the Americas: A Chronology of Armed Conflict in the New World, 1492 to the Present. Santa Bárbara: ABC-CLIO.

Encina, Francisco. 1983. Historia de Sudamérica. Sociedad Editora Revista Ercilla Ltda S. A.

Freyre, Gilberto. 1980. Casa-Grande \& Senzala: Formaşao da família Brasileira sob o Regime de Economía Patriarcal.1980, Río de Janeiro: INL-MEC.

Furtado, Celso. 2006. Formaçao Econômica do Brasil. São Paulo: Companhia das Letras.

Gomes Laurentino. 2013. 1889. São Paulo: Globo.

Pigna, Felipe. 2004. Los mitos de la bistoria argentina Buenos Aires: Grupo Editorial 
¿Qué América es ésta? Sobrevivencias de la colonización europea de Indoamérica, ejemplificando con los casos de Brasil y Argentina

Ribeiro Darcy, Norma. 1995. O povo brasileiro. A formação e o sentido do Brasil. São Paulo: Companhia das Letras.

Ribeiro Darcy, Norma. 1979. O Processo Civilizatório. Etapas da evoluçao sóciocultural. Rio de Janeiro: Vozes.

Ribeiro Renato, Janine. 2003. "Brasil: Entre a Identidade Vazia e a Construção do Novo" Cuadernos IHU Idéias, 6. Instituto Humanitas Unisinos.

Romero, José Luis. 2011. Vida histórica, ciudad y cultura. Buenos Aires: Universidad de San Martín.

Rins, E. Cristina y Winter, María Felisa. 1997. La Argentina: una historia para pensar 1776-1996. Buenos Aires: Kapelusz.

Seeber, Francisco. 1984. "Solidez de la estructura social argentina" Universitas, $72 / 73$.

Nogueira de Silva, Marilene Rosa. 1988. Negro na rua. A nova face da escravidão. São Paulo: Editora HUCITEC.

Fronteiras, Sem. 2010. "Da utopia as perspectivas. A integraçao LatinoAmericana" Revista de ciência, tecnologia e inovação. São Paulo.

Sierra, Vicente D. 1967. Historia de la Argentina (1492-1852). Buenos Aires: Editorial Científica Argentina.

Vizer, Eduardo A. 2016. "Representaciones sociales de la dictadura, la democracia y la memoria. El caso argentino" Csikós, Zsuzsanna (ed.). Transiciones: de la dictadura a la democracia. Szeged: Americana eBoooks. 165-177. 